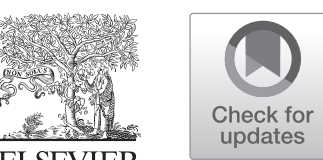

\title{
Challenges of Organ Donation: Potential Donors for Transplantation in an Area of Brazil's Northeast
}

\author{
B.B.O. Marinho ${ }^{a}$, A.T.F. Santos ${ }^{\mathrm{b}}$, A.S. Figueredo ${ }^{\mathrm{b}}$, L.S.A.B. Cortez ${ }^{\mathrm{b}}$, M.C.A. Viana ${ }^{\mathrm{b}}$, G.M. Santos ${ }^{\mathrm{a}}$, \\ J.W.S. Brito ${ }^{a}$, V.C.F. Rebouças ${ }^{\mathrm{b}}$, and P. Braga-Neto ${ }^{\mathrm{c}, \mathrm{d}, *}$

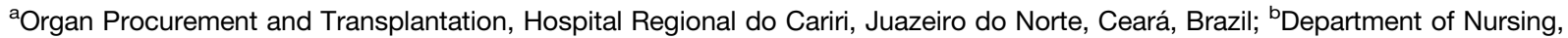 \\ Universidade Regional do Cariri, Crato, Ceará, Brazil; ' Center of Health Sciences, Universidade Estadual do Ceará, Fortaleza, Ceará, \\ Brazil; and ${ }^{\mathrm{d} D e p a r t m e n t}$ of Clinical Medicine, Universidade Federal do Ceará, Fortaleza, Ceará, Brazil
}

\begin{abstract}
Background. New strategies to manage the pool of potential donors are needed to increase organ donation rates. The purpose of the study was to identify the main causes of lack of organ donation and to identify the sociodemographic and clinical profiles of potential organ donors in an area of northeastern Brazil.

Methods. We conducted a cross-sectional, retrospective, observational study between November 2015 and January 2017.

Results. A total of 150 potential donors were included in the sample. The main cause of death among potential donors was hemorrhagic stroke (35.3\%). Hypertension was the most prevalent comorbidity $(25.6 \%)$. Family member's refusal was cited as the most common reason for not performing organ donation (49.4\%). Among the causes of family member's refusal, the most prevalent was declaration of non-consent in life $(23 \%)$, followed by family disagreement $(20.3 \%)$.

Conclusion. There is clearly a need for public educational efforts with regard to organ donation. Educational advertising campaigns can help improve the authorization rate of organ donation.
\end{abstract}

$\mathbf{T}$ HE CURRENT practice of organ transplantation and its application in disease treatment has been among the greatest advances in the history of medicine. In Brazil, transplantation emerged in the 1960s and has increased significantly in frequency in recent years. Organ transplantation is the best therapy for terminal and irreversible organ failure. It is can also improve the patient's quality of life [1].

Brazil has one of the largest public organ and tissue transplant programs in the world, and has the second largest kidney and liver transplantation program in the world. The Brazilian Public Health System supports the majority of transplants, but it depends on sufficient donation of organs [2-4].

Many initiatives and campaigns have been put into place to increase organ donation in Brazil, but donation remains insufficient [5-7]. It is of paramount importance to identify the barriers in this process.

This study is relevant to public health in Brazil, which faces an increasing rate of chronic terminal diseases. New strategies to manage the pool of potential donors are needed to increase organ donation rates. The knowledge of the main causes of non-organ donation could identify failures in the process, and from these data, guide the development of future strategies to increase the numbers of organ transplantions. The aim of the study was to identify the main causes of lack of organ donation and to characterize the sociodemographic and clinical profile of potential donors from the area near Cariri, in Ceará, Brazil.

\section{METHODS}

We conducted a cross-sectional, retrospective, observational study between November 2015 and January 2017. The study was

*Address correspondence to Pedro Braga-Neto, MD, PhD, Universidade Estadual do Ceará, Center of Health Sciences, Avenida Dr. Silas Munguba, 1700, Itaperi CEP 60.714-903, Fortaleza, CE, Brazil. E-mail: pedro.braga@uece.br 
performed within the Organ Procurement Organization (OPO) of the region of Cariri, located in the southern portion the State of Ceará. There are 2 other OPOs in Ceará. Our sample consisted of 150 medical records. Data on sociodemographics and cause of brain death were collected. The local research ethics committee of the participating institutions approved the study. All subjects provided informed consent.

\section{RESULTS}

We identified 326 brain death (BD) protocols, of which 150 $(41.7 \%)$ remained as potential donors. Table 1 presents the sociodemographic profile of the potential organ donors. There was predominance of males $(n=91,60.7 \%)$, age $>62$ years $(\mathrm{n}=53,35.4 \%)$, nonwhite $(\mathrm{n}=77,51.4 \%)$, and married $(\mathrm{n}=25,16.9 \%)$.

Table 2 presents the clinical features of potential organ donors. Hemorrhagic stroke (HS) was the main cause of BD $(\mathrm{n}=53 ; 35.3 \%)$, followed by the traumatic brain injury (TBI) $(\mathrm{n}=38,25.3 \%)$ and ischemic stroke (IS) $(\mathrm{n}=36$, $24 \%$ ). Regarding the past history, systemic arterial hypertension (SAH) was the most prevalent comorbidity (25.6\%).

Table 3 presents the reasons for refusal of organ donations. Family members' refusal was the main cause $(49.4 \%, \mathrm{n}=74)$, followed by cardiorespiratory arrest and medical contraindications. Due to the high rate of refusals, we sought to identify the reasons for family refusal. Patient declaration of nonconsent in life $(23 \%)$ followed by family disagreement $(20.3 \%)$ were the main reasons for family refusal.

\section{DISCUSSION}

The potential donor profiles in the present study resemble those observed in other studies conducted in Brazil. The predominance of male gender corroborates with research

Table 1. Sociodemographic Profile of Potential Organ Donors

\begin{tabular}{lcc}
\hline Characteristics & $\mathrm{n}$ & $\%$ \\
\hline Gender & & \\
Male & 91 & $60.7 \%$ \\
Female & 59 & $39.3 \%$ \\
Age (years) & & \\
$0-14$ & 2 & $1.3 \%$ \\
$15-30$ & 28 & $18.7 \%$ \\
$31-46$ & 35 & $23.3 \%$ \\
$47-62$ & 32 & $21.3 \%$ \\
$>62$ & 53 & $35.4 \%$ \\
Ethnicity & & \\
White & 29 & $19.3 \%$ \\
Black & 14 & $9.3 \%$ \\
Brown & 77 & $51.4 \%$ \\
Not known & 30 & $20 \%$ \\
Marital state & & \\
Single & 15 & $10 \%$ \\
Married & 24 & $16 \%$ \\
Widowed & 4 & $2.7 \%$ \\
Divorced & 1 & $0.6 \%$ \\
Stable union & 3 & $2 \%$ \\
Not known & 103 & $68.7 \%$ \\
\hline
\end{tabular}

Table 2. Clinical Features of Potential Organ Donors

\begin{tabular}{lcc}
\hline \multicolumn{1}{c}{ Characteristics } & $\mathrm{n}$ & $\%$ \\
\hline Cause of death & & \\
$\mathrm{HS}$ & 53 & $35.3 \%$ \\
$\mathrm{IS}$ & 36 & $24 \%$ \\
$\mathrm{TBI}$ & 38 & $25.3 \%$ \\
Tumor & 4 & $2.7 \%$ \\
$\mathrm{HIE}$ & 5 & $3.3 \%$ \\
Other & 14 & $9.4 \%$ \\
Blood type $_{\mathrm{A}^{+}}$ & & \\
$\mathrm{A}^{-}$ & 40 & $26.6 \%$ \\
$\mathrm{~B}^{+}$ & 3 & $2 \%$ \\
$\mathrm{~B}^{-}$ & 11 & $7.3 \%$ \\
$\mathrm{AB}^{+}$ & 1 & $0.7 \%$ \\
$\mathrm{AB}^{-}$ & 7 & $4.7 \%$ \\
$\mathrm{O}^{+}$ & 1 & $0.7 \%$ \\
$\mathrm{O}^{-}$ & 63 & $42 \%$ \\
Not known & 3 & $2 \%$ \\
Personal background & 21 & $14 \%$ \\
DM & & \\
SAH & 10 & $12.2 \%$ \\
Smoking & 21 & $25.6 \%$ \\
Alcoholism & 18 & $15.8 \%$ \\
\hline Abbre & 20 &
\end{tabular}

Abbreviations: IS, ischemic stroke; SAH, systemic arterial hypertension; HS, hemorrhagic stroke; DM, diabetes mellitus; HIE, hypoxic-ischemic encephalopathy; TBI, traumatic brain injury.

carried out in the same area of Ceará and other cities in Brazil [6-8]. Moreover, the Brazilian Registry of Transplants also describes males as the primary donor source [3]. There is, however, a higher incidence of mortality in males [8]. In Spain, India, and Puerto Rico, there is also a predominance of potential donors in the male population [9-11]. One study from France evaluated data between 2012 and 2013 and identified a male:female ratio of 1.4:1 for potential donors, which was supported by our findings [12].

Regarding the age group of the potential donors, data we obtained are in contrast to a previous study performed in

Table 3. Reasons of Declining Organ Donation and Family Refusal

\begin{tabular}{lrc}
\hline \multicolumn{1}{c}{ Characteristics } & $\mathrm{n}$ & $\%$ \\
\hline Reason for not establishing & & \\
Family refusal & 74 & $49.4 \%$ \\
Unstable hemodynamics & 2 & $1.3 \%$ \\
Cardiac arrest & 36 & $24 \%$ \\
Contraindication & 20 & $13.3 \%$ \\
Nonconclusive diagnosis & 12 & $8 \%$ \\
Not informed & 2 & $1.3 \%$ \\
Others & 4 & $2.7 \%$ \\
Familiar refusal reasons & & \\
Nondonor in life & 17 & $23 \%$ \\
Familiar disagreement & 15 & $20.3 \%$ \\
Nonfavorable familiars & 11 & $14.9 \%$ \\
Not informed & 7 & $9.4 \%$ \\
Service dissatisfaction & 6 & $8.1 \%$ \\
Long time in process & 5 & $6.7 \%$ \\
Body integrity & 4 & $5.4 \%$ \\
Others & 9 & $12.2 \%$ \\
\hline
\end{tabular}


Ceará, which indicated the most prevalent age group was 15 to 28 years [3]. In a study held in Santa Catarina the mean age was 42.8 years [13]. In São Paulo, the most common age range of potential donors was 41 to 60 years [14]. Another study carried out between 2012 and 2013 in France, the average age was 50 years [12]. Our data may be the result of the aging of the Brazilian population, which has undergone an increase in life expectancy in recent years, and also the modification of selection criteria for donors, which were previously more restrictive with regard to age $[7,8]$.

Potential donor age expansion is also justified by the relationship with medical history. In the age group portrayed, there is greater vulnerability to the development of chronic diseases in older people. Indeed, comorbid health conditions disproportionately affect older patients. In a study of the nutritional profile of the elderly there was a high prevalence of SAH and diabetes mellitus (DM) [15].

Organ application with expanded criteria bring with them a dilemma, and the use of these organs can increase the chances of failure at transplantation, and also present a higher risk for the recipient and possible poorer long-term graft function [16]. Although use of the expanded criteria is legal by applicable national laws, due to scarce number of organ forward the wait queues for transplantation, thus to increase the number of donation engage use of doners considering frontier or also titled doners with expanded criterion $[16,17]$.

The ethnicity of potential donors in this study reflects Ceará's state government registry. In Ceará, there is a predominance of nonwhites [3]. In other cities in northeastern Brazil, nonwhite ethnicity is also the most prevalent [18]. It is also noteworthy that, in Brazil, the nonwhite population has less access to health and education, which increases the chances of disease.

Regarding cause of death of the potential donors, our data are similar to those of previous studies. TBI has decreased as the main cause of brain death and has been replaced by diseases of the circulatory system, including stroke $[5,6,13,18]$. This result suggests a modification in the profile of potential donors. In recent years there have been changes in the epidemiologic patterns and demographics in the country, as well as changes in causes of death in the Brazilian population. A potential bias of our sample is the location of data collection. The hospital is a reference in the region for trauma and stroke, which could explain the data obtained.

Family member refusal was pointed out as the most common reason for not carrying out organ donation. Previous works have shown similar findings. In one study performed in southern Brazil, the family refusal rate was even higher [13]. Other studies carried out in Brazil demonstrated family refusal as of the main limiting factors in the low availability of organs and tissues for purposes of transplantation $[7,18,19]$. One study that evaluated the causes of failure of organ donation at a university hospital in Brazil noted a very low organ donation rate of only $19.5 \%$. Family refusal was cited as the main reason, occurring in $37.2 \%$ [20].
The high rate of family refusal for organ donation has also been reported in other countries. Family refusal was $87 \%$ in a study from India [11]. In Hong Kong, in a recent large study involving 1740 patients, the family authorization rate for organ donation was only $36.8 \%$ [21]. In a French study, $34 \%$ of the causes of non-donation were due to family refusal [12]. The UK has a refusal rate for organ donation considered to be among the highest in Europe, with $42 \%$ refusals before organ donation request [22].

The reasons for family refusal are related to different factors, among them cultural and religious issues, misinformation, inappropriate approaches on the part of professionals, and the lack of knowledge of the patient's wishes $[6,7,19]$.

In analyzing the reasons for refusal of organ donation, we noticed a strong desire for non-donation among potential donors during their life. The expressed wish in life is one of the main factors for deciding on organ donation [6]. In France, family refusal rates were similar to what we observed. Regarding reason for refusal, 39\% of family members indicated written refusal or that this issue had been spoken about in life. Twenty-eight percent of refusals were to keep the integrity of the body and $11 \%$ were related to religious belief [12].

Family disagreement regarding the donation decision is commonly related to the lack of consensus presented by family members with respect to organ and tissue donation [19]. In a study from India, disagreement between relatives was found to generate a consensus of refusal to donate organs [11].

Family members face a major dilemma: donate, and help other people, or protect the body of the deceased. Generally, the family will respect the patient's wish [23]. In Guanajunto, Mexico, 642 individuals $>15$ years old were surveyed, with $>80 \%$ showing strong tendency to donate their own organ, but this figure decreased significantly when it pertained to donation of organs of a family member. Thus, although most people wish to donate, this is not reflected in the country's rate of donation. Personal beliefs, fear, and not knowing the potential organ recipient were among the other reasons listed for family refusal to donate in the Mexican study. However, $94.5 \%$ of the population indicated a wish to receive an organ if necessary [24].

It is important to realize the gap that exists between the number of people favorable to donation and those who truly authorize the procedure [18]. Meetings, advertising campaigns, lectures, and media can be used to promote issues related to the donation and transplantation of organs. Also, there is a need for training of professionals and an improved approach to family members. Both education of the public about maintaining a positive attitude toward organ donation and education of health professionals are key factors for increasing the rate of organ donation.

In conclusion, family refusal was found to be the greatest barrier to organ donation. Our study suggests subsidizing creation of new strategies for the national policy for organ 


\section{donation with the aim of increasing the number of dona- tions/transplants.}

\section{REFERENCES}

[1] Cappellaro J, Silveira RSd, Lunardi VL, Corrêa LVO, Sanchez ML, Saioron I. Intra-hospital committee for donation of organs and tissues for transplant: ethical issues. Rev Rede Enfermagem Nordeste 2014;15:949-56.

[2] Dalbem GG, Caregnato RCA. Organ and tissue donation for transplant: family refusal. Texto Contexto Enferm Florianópolis 2010;19:728-35.

[3] Rodrigues TB, Vasconcelos MIO, Brito MCC, et al. Profile of potential organ donors in a reference hospital. Ceará. Rev Rede Enfermagem Nordeste 2013;14:713-9.

[4] Westphal GA, Garcia VD, Souza RL, et al. Guidelines for the assessment and acceptance of potential brain-dead organ donors. Rev Bras Ter Intensiva 2016;28:220-5.

[5] Vasconcelos QLDAQ, Freire ILS, Araújo RO, et al. Laboratorial evaluation of potential donors of organs and tissues for transplantation. Rio Grande do Norte. Rev Rede Enfermagem Nordeste 2014;5:273-81.

[6] Freire ILS, Vasconcelos QLDAQ, Torres GV, Araújo EC, Costa IKF, Melo GSM, et al. Structure, process and outcomes of organ and tissue donation for transplantation. Rev Bras Enferm 2015;68:837-45.

[7] Rosário EM, Pinho LG, Oselame GB, Neves EB. Family refusal facing a potential organ donor. Cad Saúde Coletiva 2013;21: 260-6.

[8] Moura EC, Gomes R, Falcão MTC, Schwarz E, das Neves AC, Santos W. Gender inequalities in external cause mortality in Brazil, 2010. Cien Saude Colet 2015:3:779-88.

[9] Torres EA, Martinez NA, Martinez P, et al. Profile of the average organ non-donor: can it be used predictively? P R Health Sci J 2014;33:129-31.

[10] Escudero D, Valentin MO, Escalante JL, et al. Intensive care practices in brain death diagnosis and organ donation. Anaesthesia 2015;70:1130-9.

[11] Kumar V, Ahlawat R, Gupta AK, et al. Potential of organ donation from deceased donors: study from a public sector hospital in India. Transpl Int 2014;27:1007-14.
[12] Henon F, Le Nobin J, Ouzzane A, Villers A, Strecker G, Bouye S. [Factors influencing the choice of nondonor families in a French organ-harvesting center]. Prog Urol 2016;26:656-61 [in French].

[13] Noronha MGO, Seter GB, Perini LD, et al. Study of the profile of organ and tissue elective donors, and the reasons for nondonation, at the Hospital Santa Isabel, Blumenau, Santa Catarina. Rev AMRIGS Porto Alegre 2012;56:199-203.

[14] Moraes EL, Silva LB, Moraes TC, Paixao NC, Izumi NM, Guarino Ade J. The profile of potential organ and tissue donors. Rev Lat Am Enfermagem 2009;17:716-20.

[15] Scherer R, Scherer F, Conde SR, et al. Nutritional status and prevalence of chronic diseases among elderly in the countryside of Rio Grande do Sul state. Brazil. Rev Bras Geriatr Gerontol 2013;16:769-79.

[16] Bacchella T, et al. Marginal craft increase early mortality in liver transplantation. Sao Paulo Med J 2008;126:161-5.

[17] McKeown DW, Bonser RS, Kellum JA. Management of the heartbeating brain-dead organ donor. $\mathrm{Br} \mathrm{J}$ Anaesth 2012;108(suppl 1):i96-107.

[18] Barreto BS, Santana RJB, Nogueira EC, Fernandez BO, Brito FPG. Factors associated with refusal to donate organs in the state of Sergipe, Brazil. Vitória. Rev Bras Pesq Saúde 2016;18:40-8.

[19] Donoso MT, Gonçalves VAMS, Mattos SS. The patient's family and the organ donation: a literature integrative revision. Rev Enferm Cent Oeste Min 2013;3:597-604.

[20] Dell Agnolo CM, de Freitas RA, Toffolo VJ, et al. Causes of organ donation failure in Brazil. Transplant Proc 2012;44: 2280-2.

[21] Lee A, Ni MY, Luk AC, et al. Trends and determinants of familial consent for corneal donation in Chinese. Cornea 2017;36: 295-9.

[22] Hulme W, Allen J, Manara AR, Murphy PG, Gardiner D, Poppitt E. Factors influencing the family consent rate for organ donation in the UK. Anaesthesia 2016;71:1053-63.

[23] de Groot J, van Hoek M, Hoedemaekers C, et al. Decision making on organ donation: the dilemmas of relatives of potential brain dead donors. BMC Med Ethics 2015;16:64.

[24] Lopez-Falcony R, Ramirez-Orozco R, Ortiz-Aldana FI, et al. Attitudes toward organ donation and transplantation in Guanajuato, Mexico. Transplant Proc 2016;48:556-8. 